LETTERS TO THE EDITOR

If you have a burning desire to respond to a paper published in Thorax, why not make use of our "rapid response" option? Log on to our website (www.thoraxjnl.com), find the paper that interests you, and send your response via email by clicking on the "eletters" option in the box at the top right hand corner.

Providing it isn't libellous or obscene, it will be posted within seven days. You can retrieve it by clicking on "read eletters" on our homepage.

The editors will decide as before whether to also publish it in a future paper issue.

\section{Usefulness of GOLD classification of COPD severity}

In 2001 the US National Heart, Lung and Blood Institute (NHLBI) and the World Health Organization announced guidelines for the diagnosis, management, and treatment of COPD (Global Initiative for Chronic Obstructive Lung Disease, GOLD).' One key aspect of these guidelines is that COPD is classified by severity into five stages which constitute the basis of treatment recommendations. However, to date there has been little evidence for the usefulness of these severity stages.

We retrospectively reviewed 1000 patients with COPD diagnosed clinically in 2001; 500 patients originated from a pulmonary rehabilitation hospital. Patients' symptoms (based on a standardised interview), findings of a standardised lung examination, lung function

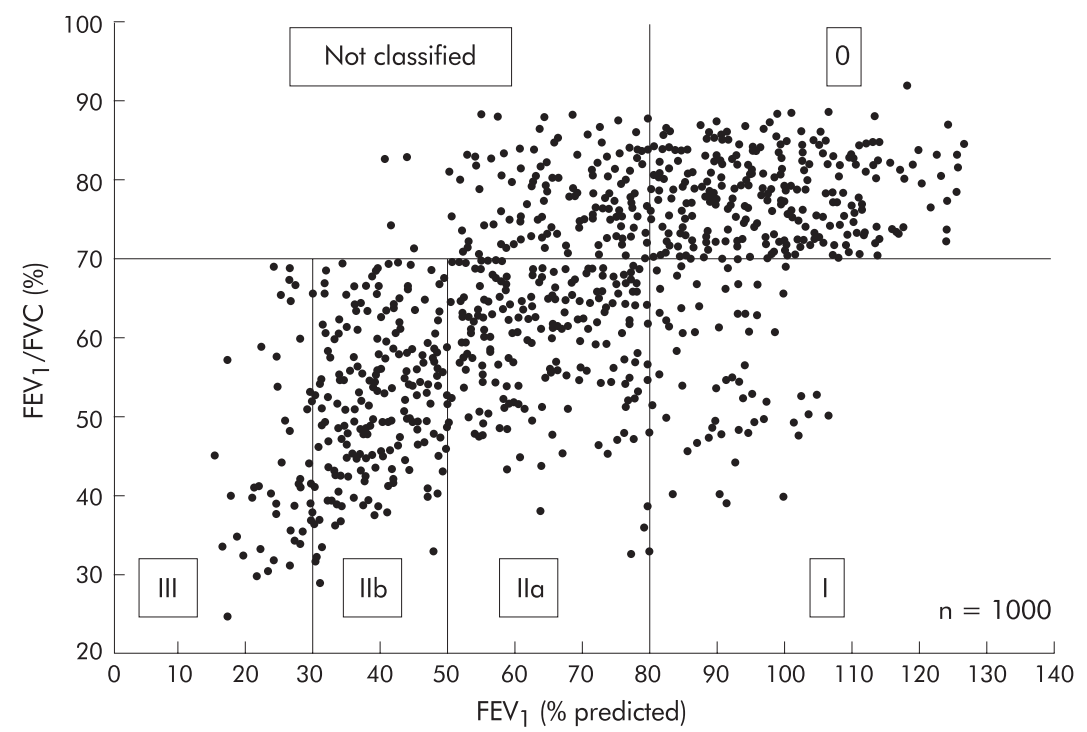

Figure 1 Plot of \% predicted forced expiratory volume in 1 second $\left(\mathrm{FEV}_{1}\right)$ against the ratio of $\mathrm{FEV}_{1}$ to forced vital capacity (FVC) (\%) of the total population ( $\left.n=1000\right)$. data, and chest radiographic findings are routinely documented in a database. The inclusion criteria were symptoms of COPD (chronic cough with chronic sputum production for more than 2 years) and radiographic findings of COPD (hyperinflation, diaphragmatic flat(variability of spirometric parameters, improvement in forced expiratory volume in 1 second $\left(\mathrm{FEV}_{1}\right)$ of $>20 \%$ after inhalation of $\beta_{2}$ agonists, symptoms predominantly at night, seasonal allergies, allergic rhinitis, or eczema) were excluded from the study, as were those in whom FEV and forced vital capacity (FVC) differed by more than $5 \%$ according to the American Thoracic Society (ATS) guidelines and patients with an abnormal chest radiograph or chronic cough caused by a disease other than COPD.

FEV , and FEV,/FVC were determined three times. The predicted values for $\mathrm{FEV}_{1}$ were taken from the European Respiratory Society (ERS) guidelines. ${ }^{3}$ The individual values of $\mathrm{FEV}_{1}$ and $\mathrm{FEV}_{1} / \mathrm{FVC}$ for all patients are shown in fig 1. Almost $14 \%$ of patients clinically diagnosed as having COPD could not be classified because they had an $\mathrm{FEV}_{1} / \mathrm{FVC}$ ratio of $>70 \%$, despite having a reduced $\mathrm{FEV}_{1}(<80 \%$ predicted). This combination is not represented in the GOLD classification. Less than $5 \%$ of all patients were classified as GOLD stage I.

The finding that the GOLD classification missed an important subgroup of patients with mild COPD challenges any proposed advantage of this classification scheme over existing guidelines from the $\mathrm{ATS}^{4}$ and ERS. Only six patients not classified as having COPD by GOLD were missed using the ATS criteria (stage I: $\mathrm{FEV}_{1} \geqslant 50 \%$ ) and ERS criteria (mild: FEV $\leqslant 70 \%$ and $\mathrm{FEV}_{1} / \mathrm{NC}>88 \%$ for men and $>89 \%$ for women). Obviously, any arbitrary classification of a continuous variable such as $\mathrm{FEV}_{1}$ and $\mathrm{FEV}, / \mathrm{FVC}$ results in a borderline group of patients. The GOLD classification, however, provides no guidance tening). Patients with a history of asthma as to the further diagnosis of the unclassified subgroup (fig 1). Our results also show that stage I disease $\left(\mathrm{FEV}_{1} / \mathrm{FVC}<70 \%\right.$ and $\mathrm{FEV}_{1}$ $>80 \%$ predicted) was very rare, constituting only $4-5 \%$ of the patients. This indicates that the distribution of the stages, especially stage $\mathrm{I}$, is inhomogeneous.

Despite its retrospective design, this study was strengthened by the fact that lung function data, chest radiographic findings, and the results of a standard clinical examination were available for all patients. It therefore offers the chance to investigate the clinical impact of the GOLD classification, especially in patients with mild COPD.

Our study therefore suggests that GOLD criteria miss an important subgroup of patients with clinically diagnosed COPD, which reduces its usefulness as a clinical tool.

D Köhler

Krankenhaus Kloster Grafschaft, D-57392

Schmallenberg, Germany

J Fischer, F Raschke

Klinik Norderney, D-26548 Norderney, Germany

B Schönhofer

Abteilung für Pneumologie und Intensivmedizin, Klinikum Hannover, Podbielskistrasse 380, 30659 Hannover, Germany

Correspondence to: Dr D Köhler, Krankenhaus Kloster Grafschaft, D-57392 Schmallenberg, Germany; D.Koehler@fkkg.de

\section{References}

1 Pauwels RA, Buist AS, Calverley PM, et al. Global strategy for the diagnosis, management, and prevention of chronic obstructive pulmonary disease. NHLBI/WHO Global Initiative for Chronic Obstructive Lung Disease (GOLD) Workshop summary. Am J Respir Crit Care Med 2001;163:1256-76

2 American Thoracic Society. Standardization of spirometry, 1994 update. Am J Respir Crit Care Med 1995:152:1107-36.

3 Quanjer PH, Dalhuijsen A, Van Zomeren BC. Summary equations of reference values. Bull Eur Physiopathol Respir 1983;19:45-51

4 American Thoracic Society. Standards for the diagnosis and care of patients with chronic obstructive pulmonary disease. Am J Respir Crit Care Med 1995;152:S77-121.

5 Siafakas NM, Vermeire P, Pride NB, et al. Optimal assessment and management of chronic obstructive pulmonary disease (COPD). The European Respiratory Society Task Force. Eur Respir J 1995;8: 1398-420.

\section{Sahaja yoga in asthma}

Since the publication of our paper on Sahaja yoga in the management of moderate to severe asthma ${ }^{1}$ we have received a large number of enquiries. One issue that has been raised about the technique used in the study warrants clarification and further acknowledgement.

The Sahaja yoga meditation technique used in the study was not developed by the authors. The technique was taught to subjects in the intervention group by experienced Sahaja yoga practitioners free of charge. The technique itself was developed by yoga expert $\mathrm{H} \mathrm{H}$ Shri Mataji Nirmala Devi and she permitted the investigators to conduct the study on the following reasonable conditions: (1) that no part of the technique be misrepresented, misappropriated or commercialised by the investigators; (2) that the founder and practitioners of the process be appropriately 
acknowledged as the true source and custodians of the technique and its associated knowledge; and (3) that it be made clear that the Sahaja yoga technique is, as a matter of policy and philosophical conviction, always made available free of charge.

The authors sincerely regret any misunderstanding that may have led readers or members of the public to believe otherwise. They sincerely and gratefully acknowledge the important and crucial role played by $\mathrm{HH}$ Shri Mataji Nirmala Devi and the Sahaja yoga practitioners of Australia in the execution of this study, and sincerely regret not having made more appropriate acknowledgements in the original article.

R Manocha

Natural Therapies Unit, Royal Hospital for Women Locked Bag 2000, Randwick 2031, Australia r.manocha@unsw.edu.au

\section{Reference}

1 Manocha R, Marks GB, Kenchington P, et al. Sahaja yoga in the management of moderate to severe asthma: a randomised controlled trial. Thorax 2002:57: 110-5.

\section{Homeopathy in childhood asthma}

We read with interest the article by White et al on the use of homeopathy as an adjunct in the treatment of childhood asthma. ${ }^{1}$ We also obtained negative findings in an open study in which we assessed the effects of homeopathy on spirometry and exhaled nitric oxide (eNO) in children with stable asthma.

Twelve asthmatic children ( 4 boys, median age 13.5 years, range $7-18$ ) who satisfied the following inclusion criteria were recruited: ( 1 ) stable asthma with no clinical indication for change in treatment, on any dose of inhaled corticosteroid and any other asthma medications; (2) raised eNO level at the start of the study despite clinical stability; (3) identifiable sensitivity to house dust mite (HDM, $\mathrm{n}=3$ ) or cat and HDM $(\mathrm{n}=9)$ by history and skin prick test (SPT); (4) no hospital admission or emergency department attendance for asthma in the previous 3 months; (5) no history of consumption of oral corticosteroid in the previous 3 months; (6) no homeopathic treatment within the previous 6 months, allergen desensitisation within the previous year, or HDM avoidance measures or removal of household pet to which the subject had a positive SPT in the previous 3 months.

At baseline all recruited patients underwent SPT if this had not been done within the previous 2 years, eNO measurement (NIOX, Aerocrine, Sweden), and spirometric testing (Vitalograph, Buckingham, UK) measuring forced expiratory volume in l second ( $\mathrm{FEV}$ ). The mean of three best efforts was recorded and the result was expressed as percentage predicted. The homeopathic remedy was prescribed according to the child's SPT result. This was a preparation of HDM or cat dande (or both, if appropriate) in the form of two lactose globules. The preparation was made up according to the principles laid out in the British Homeopathic Pharmacopoeia. The patients were told to take the globules daily for the next 4 weeks while continuing with the same conventional asthma treatment. A diary was given to each child to encourage compliance and to document any breakthrough symptoms or side effects from the remedy during the study period. The subject were told to return for eNO measurement and spirometric assessment after 4 weeks (visit 1) on the homeopathic remedy, and to return again 4 weeks later (visit 2 ) to assess the response after stopping the remedy. The spirometric test results of one patient from the first and second visits were missing.

No side effects were reported and all subjects were compliant with the homeopathic remedy. Using the Wilcoxon signed ranks test, there was no significant difference at baseline and at visits 1 and 2 in $\mathrm{FEV}_{1}(86 \%$ (interquartile range (IQR) 81.1-93.3) v 89\% (85.0-100.0) v 85\% (74.0-89.0), respectively) and eNO (54 ppb (IQR 36.2-99.6) v $68 \mathrm{ppb}$ (37.0-87.0) v $76 \mathrm{ppb}$ (43.6-131.4), respectively). This could be because of the small sample size or because the homeopathic remedy genuinely did not have any antiinflammatory effect.

This study provides important baseline data for the calculation of the sample size needed to carry out a randomised, placebo controlled, double blind study. A sample size of 65 subjects per treatment arm would have $80 \%$ power to detect a difference of $10 \%$ in mean $\mathrm{FEV}_{1}$, assuming a standard deviation of difference of 28.86, using a paired $t$ test with a two sided significance level of 0.05 .

A M Li,

Department of Paediatrics, Prince of Wales Hospital, Shatin, NT, Hong Kong

A M Li, A Bush, N M Wilson

Department of Paediatric Respiratory Medicine Royal Brompton Hospital, London, UK

Correspondence to: Dr A M Li, Department of Paediatrics, Prince of Wales Hospital, Shatin, NT, Hong Kong; albertm68mcli@yahoo.com

\section{References}

1 White A, Slade P, Hunt C, et al. ndividualised homeopathy as an adjunct in the treatment of childhood asthma: a randomised placebo controlled trial. Thorax 2003;58:317-21

Homeopathy deserves to be scientifically appraised by good quality studies and the results published without bias which could distort future meta-analyses. The study on childhood asthma by White et al published recently in Thorax has critical flaws which seriously undermine its conclusion. The main weaknesses of the study, which were mentioned by the authors but not given due attention, were the limitations of the primary outcome measure and the mildness of the children's asthma. However, there is also concealed selection and measurement bias which could have been prevented when planning the trial.

Available guidelines for the diagnosis of asthma were not properly used for inclusion of patients, leaving room for doubt as to whether or not the included patients had asthma. Classification of asthma severity could be established at entry by using published international paediatric asthma consensus or guidelines. ${ }^{2}$ Better physiological measures could have been used-peak expiratory flow results are less reliable than forced expiratory volume in 1 second, which is the most reproducible pulmonary function parameter. ${ }^{3}$ All patients were using $\beta$ adrenergic inhalers and more than two thirds had been prescribed inhaled steroids at baseline and were well controlled; at least $50 \%$ of patients in the homeopathic group had had no asthma event in the previous 12 months, suggesting a design bias against homeopathy (ceiling effect). Sample size was calculated without a pilot study and did not allow for the fact that comparisons of the impact of asthma treatments on quality of life are likely to involve relatively small effect sizes even when one treatment is clearly superior. ${ }^{4}$

My paper on the safety of homeopathy ${ }^{5}$ is misquoted; it does not in any way imply that the rate of exacerbations is a "hallmark of successful treatment". Instead, I stated that "one needs to consider the way practitioners are informing patients of the possibility of such aggravations after using homeopathic medicines, thus creating some expectations that will fulfil what was said in the consultation".

Finally, I cannot agree with the statement that the trial was designed with the input of experienced homeopathic practitioners for optimal conditions: individualised prescription of homeopathic medicines needs a good medical understanding of asthma to discriminate between disease-specific and patientspecific or peculiar symptoms. Treatment was by non-medically trained homeopaths without proper medical supervision, and this has implications on the selection of medicines Medical doctors prescribing homeopathic medicines know what the patient has in terms of conventional diagnosis and can distinguish features typical of the disease from those specific to the individual patient. This was not adequately considered by the authors in planning the study.

Taken together, these biases seriously undermine the validity of the claimed results. Such shortcomings should be eliminated from future trials of homeopathy for asthma published by respected journals such as Thorax

F Dantas

Professor of Homeopathy, Federal University of Perlândia Visiting Professor, Federal University of São Paulo, Rua Pedro de Toledo 920, São Paulo-SP, 04039-020, Brazil; fdantas@climed.epm.br

\section{References}

1 White A, Slade P, Hunt C, et al. Individualised homeopathy as an adjunct in the treatment of childhood asthma: a randomised placebo controlled trial. Thorax 2003;58:317-21

2 National Asthma Education Program. Guidelines for the diagnosis and management of asthma. Publication No 91-3042. Bethesda, MD: National Heart, Lung and Blood Institute, National Institutes of Health, 1991

3 Enright PL, Lebowitz MD, Cockroft DW. Physiologic measures: pulmonary function tests. Am J Respir Crit Care Med 1994;149: S9-18.

4 Richards JM, Hemstreet MP. Measures of life quality, role performance and functional status in asthma research. Am J Respir Crit Care Med 1994;149: S31-9.

5 Dantas F, Rampes H. Do homeopathic medicines provoke adverse effects? A systematic review. Br Homeopath J 2000;89 (Suppl 1):35-8.

The efficacy and clinical effectiveness of homeopathy engenders considerable debate; it is therefore essential that clinical trials are accurately interpreted and reported. The recent publication by White et al has highlighted this issue.

The study - which assessed classical homeopathy as an adjunctive treatment for childhood asthma-concluded that, based on the primary outcome (the active quality of living subscale of the Childhood Asthma Questionnaire), classical homeopathy was not superior to placebo. We disagree with this conclusion. The scale used to assess the primary outcome was inappropriate; it does not distinguish between asthmatics and non-asthmatics ${ }^{2}$ and 
is more suitable as a cross sectional measure than as a longitudinal outcome, and the ability to identify any therapeutic improvement was severely reduced due to ceiling/flooring effects in both the primary and some secondary outcome data. For example, baseline scores identified that the study population had good quality of life, and that two of the three age groups studied had mild asthma. Any therapeutic improvement would therefore be hard to identify, let alone quantify.

Other design issues were apparent-for example, no data were reported on homeopathic exacerbations (an indicator of the healing response), and the security of blinding was not assessed. Yet, despite these limitations, some encouraging therapeutic effects were apparent. For example, a clinically relevant improvement in asthma severity (unadjusted scores) was seen in two of the three groups, and a favourable pattern in the days off school/days attended was seen in the homeopathic treated children (although no data were presented). conclusion to these data would be that no definitive conclusions could be drawn but that further investigation is needed. We therefore hope that the authors' inaccurate conclusions neither dampen future research nor bias future systematic reviews. ${ }^{3}$

S B Brien, G Lewith Complementary Medicine Research Unit, Royal South Hants Hospital, Southampton SO14 OYG Hampshire,UK; s.brien@soton.ac.uk

\section{References}

1 White A, Slade P, Hunt C, et al.

Individualised homeopathy as an adjunct in the treatment of childhood asthma: a randomised placebo controlled trial. Thorax 2003;58:317-21.

2 French DJ, Christie M, Snowden AJ. The reproducibility of the childhood asthma questionnaires: measures of quality of life for children with asthma aged $4-16$ years. Qual Life Res 1994;3:215-24.

3 White $\mathbf{P}$, Lewith $G$, Berman $B$, et al. Reviews of acupuncture for chronic neck pain: pitfalls in conduting systematic reviews. Rheumatology 2002;41:1224-31.

The paper by White et $a l^{1}$ in the April issue of Thorax purports to show that adjunctive homeopathic treatment has no effect on the quality of life of asthmatic children. The primary outcome measure was the active Quality of Life (QoL) scale of the Childhood Asthma Questionnaire (CAQ). This measure was inappropriate, and no such conclusion is justified. As table 1 shows, the children enrolled had QoL scores virtually identical to those of non-asthmatic children in a large
We suggest that a balanced and accurate

scale validation study cited in the paper by White et al. ${ }^{2}$ Furthermore, the CAQ QoL scale does not discriminate between non-asthmatic and mildly asthmatic children.

Similar floor and ceiling effects are seen in many of the secondary outcome measuresfor example, in the homeopathy group at entry the peak expiratory flow rate was $100.4 \%$ of expected and the median number of asthma episodes in the preceding year was zero. These are all "hard" floor/ceiling effects; no improvement at all could have been expected. There is also a strong suggestion of floor/ceiling effects in other outcomes such as days lost from school, but we cannot be certain from the published data. Other secondary outcomes show relative floor/ceiling effects-for instance, the mean final value in the CAQA parental severity score was 5.5 on a scale of 5-19. Since this was an intention to treat analysis, $20 \%$ of the values were simply pretreatment values carried forward.

Other CAQ subscales analysed as secondary outcomes consistently favour homeopathy. For the severity subscales the improvement was statistically highly significant $(p=0.01)$ with $95 \%$ confidence intervals not including zero. This again was an intention to treat analysis, and while there are good reasons for performing such analyses, effect size estimates should be based on data for subjects who have actually taken the treatment and had its impact evaluated; in this case, $20 \%$ did not. In addition, there was a floor effect (see above) in one of the severity scales. A similar pattern is seen for other subscales of the CAQ but no statistical analysis is presented.

The question most frequently posed about homeopathy is "is it all placebo effect?" Most meta-analyses have concluded that it is not. If the outcome measures which could not have improved are excluded, the results of this trial accord with those of the largest meta-analysis of homeopathy; they "are not compatible with the hypothesis that the clinical effects of homeopathy are completely due to placebo". The treatment effect size was relatively small, but classical homeopathy is a complex and non-standardised intervention. The practitioners involved had no particular experience of asthma. There is thus considerable scope for refinement.

Regrettably, the conclusions do not adequately reflect the shortcomings of the trial. The authors state that "there was no evidence of a clinically relevant change in quality of life score", but omit to mention that none was expected since the QoL scores were normal at entry. There is no reference to the many floor/ ceiling effects.

Our greatest concern is that the bias in the interpretation of the results will carry through to future meta-analyses and reviews.

Table 1 Comparison of Childhood Asthma Questionnaire (CAQ) active quality of life scores in in paper by White et al' and CAQ validation study by French et al

\begin{tabular}{|c|c|c|c|}
\hline & \multirow{2}{*}{$\begin{array}{l}\text { White et al }, n=93 \\
\text { (mean at entry) }\end{array}$} & \multicolumn{2}{|c|}{$\begin{array}{l}\text { CAQ validation study (French et } a R^{2} \text { ), } n=535 \\
\text { (median) }\end{array}$} \\
\hline & & Asthmatic & Non-asthmatic \\
\hline $\begin{array}{l}\text { CAQA: range } 10-40 \\
\text { (4-7 years) }\end{array}$ & 35.2 & 34 & 34 \\
\hline $\begin{array}{l}\text { CAQB: range } 7-35 \\
\text { (8-11 years) }\end{array}$ & 28.1 & 28 & 29 \\
\hline $\begin{array}{l}\text { CAQC: range } 8-36 \\
\text { (12-16 years) }\end{array}$ & 29.4 & No data & No data \\
\hline
\end{tabular}

Higher values indicate better quality of life.
Methods such as that developed by Jadad et $a l^{4}$ would assess this as a high quality study, and the primary outcome appears to be negative. As we have shown, this interpretation is fundamentally flawed. We believe a correction should be published which should focus on (1) the inappropriate scope of the original conclusions, and (2) clarification of the secondary outcomes and the conclusions drawn from them.

P Fisher

Director of Research, Royal London Homoeopathic Hospital, London WIW 5BP, UK;

peter.fisher@uclh.org

K Chatfield

Director of Research, Society of Homeopaths Faculty of Health, University of Central Lancashire, Preston PR 1 2HE, UK

R Mathie

Research Development Adviser, Faculty of Homeopathy, Hahnemann House, 29 Park Street West, Luton LU1 3BE, UK

\section{References}

1 White A, Slade P, Hunt C, et al Individualised homeopathy as an adjunct in the treatment of childhood asthma: a randomised placebo controlled trial. Thorax 2003;58:317-21.

2 French DJ, Christie M, Sowden AJ. The reproducibility of the childhood asthma questionnaires: measures of quality of life for children with asthma aged $4-16$ years. Qual Life Res 1994;3:215-24.

3 Linde K, Clausius N, Ramirez G, et al. Are the clinical effects of homeopathy placebo effects? A meta-analysis of placebo-controlled trials. Lancet 1997;350:834-43.

4 Jadad AR, Moore RA, Carrol D, et al. Assessing the quality of reports of randomized clinical trials: is blinding necessary? Control Clin Trials 1996;17:1-12.

The study by White et $a l^{1}$ of quality of life in children with asthma treated with homeopathy is fatally flawed. The Childhood Asthma Quality of Life instrument used was validated in a study by French et al. ${ }^{2}$ The children entered into the study by White et al had scores consistent with those of normal children who don't have asthma. For a statistically significant improvement to occur in this score, the treated group would have to develop scores of around $100 \%$-that is, better than normal non-asthmatic children. This is clearly highly unlikely. In addition, a similar "ceiling effect" applies to the peak expiratory flow readings which at entry were $100.4 \%$ and $96.9 \%$ of expected for the verum and placebo groups, respectively.

This is a very poor quality trial which does absolutely nothing to further our understanding of the potential value of homeopathic treatment in children with asthma. In fact, the press release from the journal has been picked up by the media and used to support the headline "Homeopathy of no use in asthma".

Publishing this quality of research at best does not improve our necessary evidence base and, at worst, contributes to the denial of services which may indeed be of value to patients. A close analysis of the study shows that the treatment group had a trend to better outcomes than the placebo group. If this were a pilot study, it would be indicating that there is indeed a potential benefit to asthmatic children from homeopathy which should be investigated with a proper trial of good methodological quality. 
R Leckridge

Glasgow Homeopathic Hospital, Glasgow

G12 OXQ, UK; bob.leckridge@virgin.net

\section{References}

1 White A, Slade P, Hunt C, et al.

Individualised homeopathy as an adjunct in

the treatment of childhood asthma: a

randomised placebo controlled trial. Thorax

2003;58:317-21.

2 French DJ, Christie M, Sowden AJ. The reproducibility of the childhood asthma

questionnaires: measures of quality of life for children with asthma aged $4-16$ years. Qual

Life Res 1994:3:215-24.

\section{Author's reply}

These authors are to be thanked for their contribution to the debate about the interpretation of the results of our trial, and it is conceded that ceiling effects may exist which limit the interpretation of our results. If the children were already effectively medicated, it may not have been possible to show any benefit from homeopathic treatment in quality of life. It would require a much larger study to show any differential change in conventional medication or global indicators, which were absent from the results. Because of ethical issues, it may be difficult to conduct a definitive trial in children with severe asthma.

Leckridge, Fisher et al, and Brien and Lewith suggest that we should have concentrated instead on the small changes in the severity subscales, the estimate of which is not clinically relevant. However, the severity scale measures symptoms only, and active quality of life is much more appropriate for the holistic approach of homeopathy.

The claim by Fisher et al and Dantas that the homeopaths were inadequate to the task is speculative and one we reject. Dantas would prefer us to have used more rigorous criteria for inclusion and assessment, but the study was especially designed to reflect "real life" pragmatically by rigorously applying the criteria used by the GPs, the children, and their families. We cited his paper as the only systematic and objective report on homeopathic aggravations that we were aware of and if we gave the impression that he stated that aggravations are a hallmark of success, then we regret it.

A White

Complementary Medicine, Peninsula Medical School, Universities of Exeter and Plymouth, Exeter EX2 4NT, UK; adrian.white@pms.ac.uk

\section{BOOK REVIEW}

\section{Statistics in Clinical Practice}

David Coggon. 2nd edition. London: BM Books, 2002. £14.95, 120 pp. ISBN 0727916092

This is a very clearly written introduction to statistics, suitable for medical students and doctors who need a quick update in order to understand the current literature. Professor Coggon moves rapidly through types of data (continuous, ordinal or univariate and multivariate) to methods of summarising data on which a fair amount of time is spent. Tabular and graphical (dot, line, bar and pie chart) presentations are discussed with numerous illustrations from everyday clinical practice. The interpretation of graphical data and its limitations-a very important part of understanding current medical research-are thoroughly discussed. The concept of probability is introduced and combining probabilities is explained. Sensitivity and specificity are defined here but could more appropriately be placed later as they are, in fact, properties of statistical tests. Hypothesis testing, confidence intervals, and the basis of sample size calculations (though not how to calculate the size of a sample) are also discussed. The author explains the two most common methods of statistical modelling-linear regression and survival analysis-and concludes with a section on meta-analyses and the importance of involving statisticians very early in the planning stage of a study.

This is an excellent introduction to practising statistics in medicine and will be extremely useful for medical students and clinicians alike. Medical researchers will, however, need to follow this text with a more advanced one.

T Seemungal

Barts and The London Medical School, London, UK; tseemungal@aol.com 